\title{
Abnormal glucose metabolism in patients treated with antipsychotics
}

\author{
Troubles du métabolisme glucidique chez les patients traités par antipsychotiques
}

\author{
A.J. Scheen ${ }^{\mathrm{a}}$, M.A. De Hert ${ }^{\mathrm{b}}$ \\ ${ }^{\text {a }}$ Department of medicine, division of diabetes, nutrition and metabolic disorders and division of clinical pharmacology, CHU Sart-Tilman \\ (B35), university of Liège, 4000 Liège-I, Belgium \\ ${ }^{\mathrm{b}}$ University psychiatric center, katholieke universiteit Leuven, Campus Kortenberg, Belgium
}

\begin{abstract}
Second-generation (atypical) antipsychotic medications are of great benefit to a wide variety of people with psychiatric disorders, especially patients with schizophrenia. However, one constellation of adverse effects is an increased risk of obesity, diabetes, and metabolic syndrome. Increasing numbers of reports concerning impaired glucose tolerance, diabetes, and ketoacidosis have raised concerns about a possible association between abnormal glucose metabolism and treatment with atypical antipsychotics, although the question is still debated because of the presence of many confounding factors. A close relationship between drug-induced weight gain and risk of diabetes has been reported, emphasizing the role of insulin resistance. However, some cases of diabetes developed independently of weight gain, rather rapidly and possibly progressing to ketoacidosis, thus arguing for a severe impairment of insulin secretion. Another debated question is whether diabetes risk is a class action or a differential action. Although not fully scientifically proven yet, available evidence suggests that clozapine and olanzapine have a higher propensity to induce diabetes and metabolic syndrome compared with other atypical antipsychotic drugs, risperidone and quetiapine. Despite more limited available data, amisulpride, aripiprazole and ziprazidone showed less likelihood of precipitating diabetes. Interestingly, reversibility of drugrelated diabetes has been reported with aripiprazole. The choice of atypical antipsychotic medication for a specific patient depends on many factors, but the likelihood of developing diabetes should become an important consideration. When prescribing an atypical antipsychotic, a commitment to careful baseline screening and follow-up monitoring is essential in order to mitigate the risk of developing diabetes and associated complications.
\end{abstract}

Keywords: antipsychoticsa; schizophrenia ; diabetes ; impaired glucose tolerance ; metabolic syndrome ; review

\section{Résumé}

Les antipsychotiques de seconde génération, appelés aussi antipsychotiques atypiques, ont apporté une aide précieuse dans la prise en charge de nombreux patients psychiatriques, en particulier ceux avec schizophrénie. Cependant, ils semblent associés à une constellation d'effets indésirables métaboliques, avec un risque accru d'obésité, de diabète et de syndrome métabolique. Un nombre croissant de publications à propos de cas de diminution de tolérance au glucose, de diabète et d'acidocétose chez des patients traités avec des antipsychotiques atypiques plaident pour une association causale possible entre une anomalie du métabolisme du glucose et le traitement par antipsychotique atypique, même si la question reste controversée suite à la présence de nombreux facteurs confondants. Une relation étroite entre la prise de poids induite par la médication et le risque accru de diabète a été rapportée, insistant sur le rôle de l'insulinorésistance. Pourtant, certains cas de diabète se développent indépendamment de toute prise pondérale, avec une évolution relativement rapide pouvant progresser jusqu'à une acidocétose, ce qui plaide alors pour une atteinte sévère de l'insulinosécrétion. Une autre question débattue est de savoir si le risque de diabète est un effet de classe ou propre à chaque molécule. Bien que cela ne soit pas encore parfaitement prouvé scientifiquement, les données disponibles actuellement suggèrent que la clozapine et l'olanzapine ont plus tendance à induire une diminution de la tolérance au glucose, un diabète ou un syndrome métabolique, en comparaison avec d'autres antipsychotiques atypiques comme la rispéridone et la quétiapine. Bien que les données soient plus limitées, l'amisulpride, l'aripiprazole et la ziprazidone paraissent associés à un moindre risque de précipiter un diabète. Une réversibilité du diabète sous aripiprazole a même été rapportée. Le choix d'un antipsychotique atypique pour un patient spécifique dépend de nombreux facteurs, mais la possibilité de développer un diabète doit dorénavant être prise en considération dans la décision thérapeutique. Lors de la prescription d'un antipsychotique atypique, une évaluation initiale soignée et un suivi métabolique régulier sont recommandés dans l'espoir de réduire le risque de voir se développer un diabète et les complications associées.

Mots clés : antipsychotiques ; schizophrénie ; diabète ; intolérance au glucose ; syndrome métabolique ; revue 


\section{Introduction}

In the past few years, attention has focused on a potential link between schizophrenia and diabetes, with speculation that the potential association may be stronger in patients who are prescribed atypical (also called second-generation) antipsychotic medications [1-5]. However, the evidence for such an association remains confusing and, in many instances, might be severely flawed [6]. Especially the important question whether the antipsychotic-associated increased risk of diabetes is a class effect remains largely unresolved because of numerous confounding factors and conflicting results [7,8]. In addition to diabetes per se, milder glucose dysregulation has been described in numerous patients receiving atypical antipsychotics, such as impaired fasting glucose (IFG) and/or impaired glucose tolerance (IGT) assessed during an oral glucose tolerance test (OGTT) [9-11]. A higher risk of developing a metabolic syndrome, which includes IFG in its various definitions, has also been stressed in recent studies [12-15]. Both diabetes and metabolic syndrome may contribute to the higher incidence of cardiovascular disease (CVD) in patients with schizophrenia and schizoaffective disorders. Risk for CVD and overall mortality due to CVD is elevated in patients suffering from schizophrenia compared to the general population, with mortality rates in this population being at least two times higher than in general population and CVD being responsible for as much as $50 \%$ of the excess mortality $[16,17]$. Recently, there has been an increased awareness of the physical needs of patients with mental illness and several psychiatric clinics, including ours, have set up physical health screening [11,18]. Such screening has unmasked a substantial degree of pathology, especially metabolic disturbances considered as CVD risk factors, including diabetes mellitus $[10,11,15]$. Recent guidelines proposed a careful metabolic monitoring in patients with schizophrenia and schizoaffective disorders, especially those receiving atypical antipsychotics [1,19-21].

Examination of the effects of antipsychotic agents on glucose metabolism represents the intersection of two disparate fields of research: psychiatry and diabetology. The present concise review summarizes the available piece of evidence regarding the risk of abnormal glucose metabolism in patients treated with second-generation antipsychotics, a possible new model of drug-induced diabetes [22,23].

\section{Psychiatric disorders and diabetes}

The association between diabetes mellitus and schizophrenia has been recognized for over a century [24]. The recent literature is relatively consistent in showing a prevalence rate of diabetes of about $15 \%$ in patients with schizophrenia or an increased risk of two to threefold as compared to the general population [17]. Such a high prevalence of diabetes and metabolic syndrome in schizophrenia over the course of the illness has been confirmed in a cross-sectional study performed by our group [25]. It is noteworthy that this higher prevalence of diabetes or abnormal glucose metabolism is also found in drug-naïve patients. The mechanisms that underlie the increased prevalence of diabetes in schizophrenia are multifactorial (Fig. 1). They include both genetic and environmental factors, such as less healthy lifestyle [6]. Much of the increased risk can be ascribed to traditional diabetic risk factors, such as family history (up to $50 \%$ of people with schizophrenia have a family history of type 2 diabetes), physical inactivity and poor diet. It remains unclear whether schizophrenia per se rather than its associated lifestyle and family history affects the risk of diabetes. The findings that schizophrenia is associated with diabetes have important implications for the critical analysis of reports linking antipsychotic agents with abnormal glucose metabolism. Finally, the increased incidence of diabetes in mental illness is by no means confined to schizophrenia but has also been observed with conditions such as bipolar affective disorder and schizoaffective disorders $[11,26,27]$.

Fig. 1. Underlying mechanisms resulting in a higher risk for dysglycemia and diabetes in patients with schizophrenia receiving atypical antipsychotic drugs: a multifactorial process leading to a combined defect in insulin resistance and insulin secretion. IFG: impaired fasting glucose. IGT: impaired glucose tolerance.

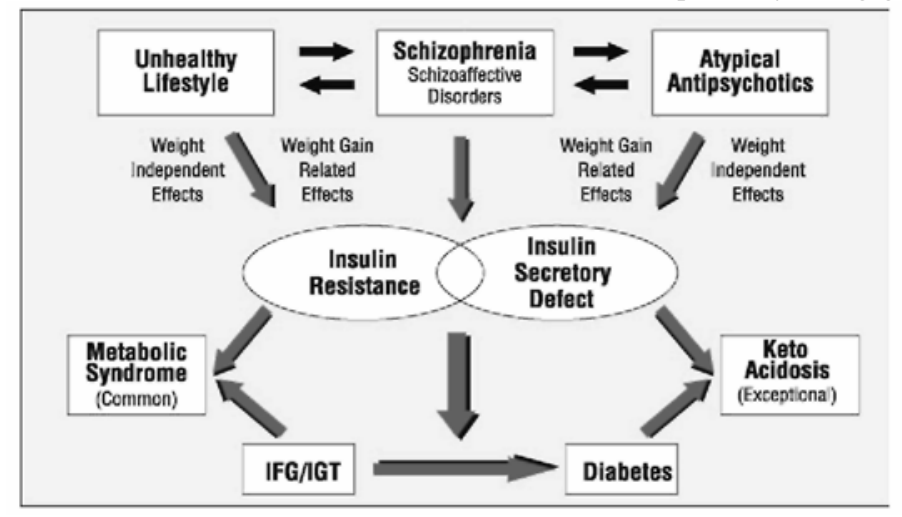




\section{Antipsychotics and glucose disturbances}

The first reports of a link between antipsychotic medication and diabetes were made in the 1950s [24]. During the 1960s, there was a general acceptance that antipsychotic drugs could cause diabetes and the term "phenothiazine diabetes" was introduced. The issue was largely forgotten, until interest was rekindled with the observation that atypical antipsychotic drugs may be associated with a higher risk of IGT and diabetes as compared to conventional antipsychotics [28-30]. Most interestingly, several observations in both humans and animals support the concept that atypical antipsychotics may have profound effects on glucose metabolism, independent of psychiatric disease [5]. Evidence for a link between antipsychotics and diabetes can be obtained from many sources, including a) anecdotal case reports; b) drug safety studies; c) pharmacoepidemiological studies; and d) prospective studies [6,7].

There are now over 60 case reports in the literature linking atypical antipsychotic therapy with diabetes [6,30]. Many of these reports show improvements in hyperglycemia following the discontinuation of therapy. Reports of hyperglycemia recurring following re-challenge provide better evidence for a causative role for the antipsychotic drugs. Many patients who developed diabetes had traditional diabetic risk factors.

Drug safety studies were mainly based on published case reports and reports made to the Food and Drug Administration (FDA) MedWatch surveillance programme [31]. Koller et al. have published several analyses of anecdotal reports of diabetes occurring with clozapine [32], olanzapine [33], risperidone [34] and quetiapine [35]. All drugs were associated with either new cases of diabetes or exacerbation of pre-existing disease, and there are reports on the fatalities associated with hyperglycemia for each drug. In these series of case reports, clozapine and olanzapine appear more frequently than the other drugs. However, the limitation of case reports should again be recognized and caution is warranted before concluding that these two drugs are more frequently associated with diabetes than the other atypical antipsychotic drugs [6].

Case-note studies have been used to determine the incidence or prevalence of diabetes among patients receiving various antipsychotic drugs [36,37]. We performed a large study using an OGTT to assess glucose abnormalities in 415 patients with schizophrenia or schizoaffective disorders treated with antipsychotics [10,11] (Table 1). A screening based on the consensus guidelines (fasting measurements) showed that diabetes was present in 12 patients $(2.9 \%)$, and IFG in another 79 patients (19.0\%). However, these cases only represented $46.2 \%$ of diabetes cases and $68 \%$ of prediabetes cases (IGT and/or IFG) of the cases identified by means of an OGTT. In total, $6.3 \%(N=26)$ met criteria for diabetes, resulting in a mean annual incidence of diabetes of $3.15 \%$. These data confirm that metabolic abnormalities are highly prevalent in a relatively young sample of schizophrenic patients treated with antipsychotics. However, all these studies cannot determine whether the increase in blood glucose was caused by the antipsychotic drug or by other factors, especially because none of them adequately controlled for the risk factors of diabetes. Nevertheless, the lack of a significant increase in mean blood glucose in comparator groups would suggest a causal relationship between atypical antipsychotics and diabetes.

Table 1 Glucose abnormalities in relation to antipsychotic treatment in a cross-sectional study of 415 patients with schizophrenia or schizoaffective disorders consecutively recruited for 2 years [10,11,25]

\begin{tabular}{lll}
\hline & \multicolumn{1}{c}{$\begin{array}{c}\text { Diabetes } \\
(N=26)\end{array}$} & \multicolumn{1}{c}{$\begin{array}{c}\text { Prediabetes } \\
(N=97)\end{array}$} \\
\hline First-generation $(N=87)$ & $3.5 \%(3)$ & $25.5 \%(22)^{*}$ \\
Amisulpride $(N=32)$ & $0 \%(0)$ & $6.3 \%(2)$ \\
Aripiprazole $(N=4)$ & $0 \%(0)$ & $0 \%(0)$ \\
Clozapine $(N=74)$ & $9.6 \%(7)$ & $40.5 \%(30)$ \\
Risperidone $(N=98)$ & $5.1 \%(5)$ & $21.4 \%(21)$ \\
Quetiapine $(N=53)$ & $9.4 \%(5)$ & $11.3 \%(6)$ \\
Olanzapine $(N=139)$ & $5.8 \%(8)$ & $23.7 \%(33)$ \\
\hline
\end{tabular}

Several pharmacoepidemiological studies examining the association between antipsychotic drugs and diabetes have produced confusing results [38-41]. The studies rely on the analysis of computerized databases of patients treated in various organizations and are limited by the quality of clinical data recorded. Nevertheless, most reported a higher risk of diabetes in patients treated with antipsychotic drugs, compared with those not receiving pharmacological treatment. In addition, the reported incidence of diabetes was higher among patients taking atypical antipsychotics, compared with conventional agents. The comparison of the various relative risk factors for diabetes according to the compound used raised more controversy, perhaps because most of these studies were funded by the pharmaceutical industry. Pharmacoepidemiological studies, by virtue of their design, can 
only show an association, but cannot prove causality [37]. In addition, each of these studies suffers from several weaknesses [6].

Prospective, randomized, controlled trials have the major advantage of avoiding some potential bias of previous studies and of minimizing missing data or information [6,7]. The results of prospective studies began to emerge rather recently [30,42]. However, none of these studies specifically set out to determine the effect of drug on glucose metabolism and therefore all of the results are subject to post-hoc analysis. They are generally of shorter duration and concerned a smaller number of patients as compared to pharmacoepidemiological studies. There are very few studies that include placebo data. Finally, few of these studies were undertaken in drug-naïve patients and therefore there is always a possibility of a carry-over effect from previous treatment. An estimate of the attributable risk of diabetes associated with atypical antipsychotics ranges from $0.05 \%$ for risperidone to $2.03 \%$ for clozapine, suggesting that the absolute excess risk associated with second-generation antipsychotics is probably low [43]. Given that this low risk must be assessed in the context of a potentially huge effect of confounding by traditional risk factors, it may be that studies will never fully resolve this issue [6]. In one of the largest randomized clinical trials (CATIE: Clinical Antipsychotic Trials of Intervention Effectiveness) comparing a first generation antipsychotic with several atypical antipsychotics (olanzapine, risperidone, quetiapine, ziprasidone), olanzapine had effects consistent with the development of the metabolic syndrome and was associated with greater increases in glycated hemoglobin and new cases requiring added glucose-lowering agents than the other study drugs [44]. In that study, ziprasidone was the only compound associated with metabolic improvement.

We performed a prospective open non-randomized study, which aimed at comparing the effects of six atypical antipsychotics on the development of a metabolic syndrome, dysglycemia (IFG/IGT) or diabetes among 238 schizophrenic patients who underwent a systematic fasting evaluation and an OGTT before and after 3 months of treatment [45]. Main results are summarized in Table 2. Aripiprazole was the only antipsychotic that was not associated to weight gain. Furthermore, it resulted in improved glucose tolerance and reduced incidence of metabolic syndrome in schizophrenic patients, including reversal of diabetes occurring with other atypical antipsychotics [46].

Table 2 Glucose dysregulation in schizophrenic patients receiving atypical antipsychotics: results of a 3-month prospective comparative open non-randomized study [45]

\begin{tabular}{|c|c|c|c|c|c|}
\hline \multirow[t]{2}{*}{ Drug } & Patient & Weight & Glucose alterations $^{\mathrm{a}}$ & New diabetes & New MetS \\
\hline & $n$ & $\begin{array}{l}\text { Change } \\
\mathrm{kg}\end{array}$ & $\begin{array}{l}\text { Incidence } \\
(\%)\end{array}$ & $\begin{array}{l}\text { Incidence } \\
\%\end{array}$ & $\begin{array}{l}\text { Incidence } \\
(\%)\end{array}$ \\
\hline Clozapine & 23 & +7.3 & +31.1 & 8.7 & 41.2 \\
\hline Olanzapine & 59 & +6.9 & +10.2 & 6.8 & 28.0 \\
\hline Quetiapine & 31 & +4.8 & +16.1 & 6.5 & 16.7 \\
\hline Risperidone & 58 & +3.6 & +6.9 & 1.7 & 13.3 \\
\hline Amisulpride & 26 & +4.7 & -3.8 & 0 & 17.6 \\
\hline Aripiprazole $^{b}$ & 41 & -4.8 & -34.1 & $0^{\mathrm{c}}$ & $0^{\mathrm{d}}$ \\
\hline
\end{tabular}

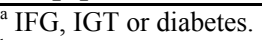

${ }^{b}$ Aripiprazole was introduced in most patients because of a worse metabolic profile with other atypical antipsychotics.

${ }^{c}$ Seven cases of diabetes reversed with aripiprazole therapy.

${ }^{\mathrm{d}}$ The prevalence of metabolic syndrome (MetS) decreased from $58.5 \%$ to $24.4 \%(P=0.0017)$.

\section{Underlying mechanisms}

Given the complexity of the pathogenesis of non-immune diabetes, it is a daunting challenge to understand the role of antipsychotics may play in the development of hyperglycemia [5]. Antipsychotic medications can affect a) energy intake and/ or expenditure; b) insulin resistance, directly or via changes in body weight and body fat distribution; and/or c) $\beta$-cell function (Fig. 1). Besides the influence of the pharmacological profile of the drug and of the underlying psychiatric disease, the response of any individual to antipsychotic treatment is determined not only by the environmental factors previously alluded to (i.e. food intake, smoking, etc.) but also by the genetic predisposition for weight maintenance, insulin resistance, and pancreatic function. In general, the rank order of risk observed for the second-generation antipsychotic medications suggests that the differing weight gain liability of atypical agents contributes to the differing relative risk of insulin resistance and hyperglycemia [4]. This would be consistent with effects observed in non-psychiatric samples, where the risk for adverse metabolic changes tends to increase with increasing adiposity. However, case reports tentatively suggest that substantial weight gain or obesity may not be a factor in up to one-quarter of cases of new-onset diabetes that occur during treatment. Pending further testing from preclinical and clinical studies, limited controlled studies support the hypothesis that clozapine and olanzapine may have a direct effect on glucose regulation independent 
of adiposity, limiting the capacity of $\beta$-cells to secrete appropriate amount of insulin $[4,5,47]$. The metabolic dysregulation with atypical antipsychotics occurs even in the absence of underlying disease as recently shown with olanzapine in a dog model [47]. Furthermore, experimental data demonstrated that low concentrations of clozapine and olanzapine can markedly and selectively impair cholinergic-stimulated insulin secretion by blocking muscarinic M2 receptors, which could be one of the contributing factors to their higher risk for producing hyperglycemia and diabetes in humans [48].

Antipsychotic-associated emergent diabetes is a complex process with at least two subgroups of patient developing diabetes mellitus [2,7]. A first subgroup concerns patients with rapid onset of diabetes after antipsychotic treatment initiation. Even if infrequent, they have been reported with ketoacidotic coma, a lifethreatening condition [31-35]. Patients with diabetic ketoacidosis were younger, less overweight at baseline and included a higher proportion of women. The pathophysiology is likely to be complex but ketoacidosis should reflect a profound defect in insulin secretion [5]. As the metabolic disorder is reversible after withdrawal of the drug, a functional defect rather than a B-cell destruction stricto sensu should be implicated. This limited, although of great interest, subgroup needs further investigations on pathophysiology and therapeutic management. The second subgroup, the larger one, has a more classical onset in which weight gain, abdominal fat deposition and other usual risk factors play a major role. One may speculate that increased insulin resistance plays a major role in the pathophysiology of diabetes occurring in those patients [4]. However, the progression to diabetes is more rapid than classically observed in obese subjects without psychiatric disease. If there are increasing evidence that there is an effect on insulin secretion leading to inadequate compensation by the B cells, it remains unknown if this effect is mediated by central or peripheral mechanisms [5].

\section{Clinical recommendations}

Given the serious health risk, patients taking atypical anti-psychotics should receive appropriate baseline screening and ongoing monitoring (Table 3) [1,19-21]. Considering the high incidence of CVD in this population, patients' psychiatric illness should not discourage clinicians from addressing the metabolic complications for which these patients are at increased risk. Especially, it is important to monitor any alteration in weight following a medication change. Pragmatic solutions for people with schizophrenia to prevent the development of diabetes should be proposed $[49,50]$.

Table 3 Comparison of the guidelines from American Diabetes Association (ADA)/American Psychiatry Association (APA) Consensus [1] and from the Belgian Consensus Group [19]

\begin{tabular}{|c|c|c|c|c|c|c|}
\hline & \multicolumn{5}{|c|}{ ADA/APA Consensus } & \multirow[t]{2}{*}{ Belgian Consensus } \\
\hline & Baseline & At 4-8 weeks & At 12 weeks & Every 3 months & Annual & \\
\hline Medical history $^{\mathrm{a}}$ & $\mathrm{x}$ & & & & $\mathrm{x}$ & Baseline, then yearly \\
\hline Weight (BMI) & $\mathrm{X}$ & $\mathrm{X}$ & $\mathrm{x}$ & $\mathrm{x}$ & & Every month $^{\mathrm{c}}$ \\
\hline Waist & $\mathrm{x}$ & & & & $\mathrm{x}$ & Every month $^{\mathrm{c}}$ \\
\hline Blood pressure & $\mathrm{x}$ & & $\mathrm{x}$ & & $\mathrm{x}$ & Quarterly \\
\hline Fasting glucose & $\mathrm{x}$ & & $\mathrm{x}$ & & $\mathrm{x}$ & 6,12 weeks, then quarterly ${ }^{\mathrm{d}}$ \\
\hline Fasting lipids & $\mathrm{x}$ & & $\mathrm{x}$ & & $x^{b}$ & Quarterly $\left(1^{\text {st }}\right.$ year $)$, then annual \\
\hline
\end{tabular}

Baseline screening measures should be obtained before, or as soon as clinically feasible after, the initiation of any antipsychotic medication [1]. Several factors should be screened that contribute to the risk of developing diabetes in patients treated with antipsychotic medication. These include family history of the disease, ethnicity, increasing age, obesity, especially abdominal adiposity, poor diet, lack of exercise, high blood pressure and dyslipidemia part of the metabolic syndrome [7]. Nutrition and physical activity counseling should be provided for all patients who are overweight or obese. Potential for weight gain may also be considered in the choice of atypical antipsychotic s and of other psychiatric and non-psychiatric medications.

Follow-up monitoring should include regular measurement of patient's weight after initiating or changing antipsychotic therapy. Fasting plasma glucose (and lipid levels and blood pressure as well) should also be assessed at regular intervals. We have shown that OGTT is able to detect abnormalities in glucose metabolism not shown by fasting measurements in numerous patients on antipsychotic medications [10,50]. For people who develop worsening glycemia while on antipsychotic therapy, it is recommended considering switching to an atypical antipsychotic medication that is associated with a lower risk of weight gain or diabetes [1]. All patients with diabetes should be referred to a clinician with experience treating people with diabetes. The benefits and 
risks of different therapeutic agents used in the treatment of diabetes and its comorbidities should be considered in the context of the patient's psychiatric condition and treatment.

There is still dispute regarding the differential effect of the various antipsychotic drugs in their ability to produce diabetes. Long-term prospective studies, preferably in drug-naive first-episode patients, need to be undertaken in order to provide definitive answers regarding significant clinical differences in the metabolic risk between various atypical antipsychotics. Our preliminary results suggest that in patients with metabolic syndrome or diabetes, the new antipsychotic agent aripiprazole seems to offer a major advantage as far as the metabolic risk profile is concerned and may be associated with improvement rather deterioration in glucose tolerance, with even reversal of drug-related diabetes [45,46].

\section{Conclusion}

Antipsychotic medication is essential for people with schizophrenia and effectiveness should be the most important consideration when selecting treatment. However, the metabolic risk should not be disregarded, especially in patients with underlying high metabolic risk because of genetic and/or environmental factors. There appears to be a higher prevalence of diabetes among patients with serious mental illnesses, especially schizophrenia, compared to the general population. Current data also seem to indicate that antipsychotic drugs may increase the risk of developing diabetes. However, what is abundantly clear from the analysis of the literature is that carefully wrought information regarding the effects of atypical antipsychotics on glucose homeostasis is still limited. Much more needs to be done to understand the central versus peripheral mechanisms of action of these agents and to discriminate between the effects of the various antipsychotics in well-performed prospective studies. Nevertheless, risk factor assessment developed for the general population appears also to be applicable to patients with serious mental illnesses. When prescribing an atypical antipsychotic medication, a commitment to baseline screening and follow-up monitoring is essential in order to mitigate the likelihood of developing diabetes and other complications. These guidelines should be implemented for and followed by psychiatrics, diabetologists and general practitioners.

\section{References}

[1] American Diabetes Association, American Psychiatric Association, American Association of Clinical Endocrinologists, North American Association for the Study of Obesity. Consensus Development Conference on antipsychotic drugs and obesity and diabetes. Diabetes Care 2004;27:596-601.

[2] Scheen AJ, De Hert M. Risque de diabète sucré sous antipsychotiques atypiques. Med Hyg (Geneve) 2004;62:1591-6.

[3] Citrome LL, Jaffe AB. Relationship of atypical antipsychotics with development of diabetes mellitus. Ann Pharmacother 2003;37:184957.

[4] Newcomer JW. Second-generation (atypical) antipsychotics and metabolic effects: a comprehensive literature review. CNS Drugs 2005;19 (Suppl 1):1-93.

[5] Bergman RN, Ader M. Atypical antipsychotics and glucose homeostasis. J Clin Psychiatry 2005;66:504-14.

[6] Holt AIG, Peveler RC. Association between antipsychotic drugs and diabetes. Diabetes Obes Metab 2006;8:125-35.

[7] Bottai T, Quintin P. Perrin. Antipsychotics and the risk of diabetes: a general data review. Eur Psychiatry 2005;20:S349-57.

[8] Ananth J, Kolli S. Atypical antipsychotic agents and increased risk of diabetes: class action or differential action? Expert Opin Drug Saf $2005 ; 4: 55-68$

[9] Jin H, Meyer JM, Jeste DV. Atypical antipsychotics and glucose dysregulation: a systematic review. Schizophr Res 2004;71:195-212.

[10] De Hert M, Van Winkel R, Van Eyck D, Hanssens L, Wampers M, Scheen A, et al. Oral glucose tolerance tests in treated patients with schizophrenia. Data to support an adaptation of the proposed guidelines for monitoring of patients on second-generation antipsychotics? Eur Psychiatry 2006;21:224-6.

[11] Van Winkel R, De Hert M, Van Eyck D, Hanssens L, Wampers M, Scheen A, et al. Screening for diabetes and other metabolic abnormalities in patients with schizophrenia and schizoaffective disorder: evaluation of incidence and screening methods. J Clin Psychiatry 2006;67:1493-500.

[12] Ryan MC, Thakore JH. Physical consequences of schizophrenia and its treatment: the metabolic syndrome. Life Sci 2002;71:249-57.

[13] Holt RIG, Peveler RC, Byrne CD. Schizophrenia, the metabolic syndrome and diabetes. Diabet Med 2004;21:515-23.

[14] McEvoy JP, Meyer JM, Goff DC, Nasrallah HA, Davis SM, Sullivan L, et al. Prevalence of the metabolic syndrome in patients with schizophrenia: baseline results from the Clinical Antipsychotic Trials of Intervention Effectiveness (CATIE) schizophrenia trial and comparison with national estimates from NHANES III. Schizophr Res 2005;80:19-32.

[15] De Hert M, Van Eyck D, Hanssens L, Peuskens H, Thys E, Wampers M, et al. Prevalence of the metabolic syndrome in patients with schizophrenia treated with antipsychotic medication. Schizophr Res 2006;83:87-93.

[16] Hennekens CH, Hennekens AR, Hollar D, Casey DE. Schizophrenia and increased risks of cardiovascular disease. Am Heart J $2005 ; 150: 1115-21$ 
[17] Henderson DC. Schizophrenia and comorbid metabolic disorders. J Clin Psychiatry 2005;66(6, Suppl): 11-20.

[18] Marder SR, Essock SM, Miller AL, Buchanan RW, Casey DE, Davis JM. Physical health monitoring of patients with schizophrenia. Am J Psychiatry 2004;161:1334-49.

[19] De Nayer A, De Hert M, Scheen A, Van Gaal L, Peuskens J, On behalf of the Consensus Group. Belgian consensus on metabolic problems associated with atypical antipsychotics. Int J Psychiatry Clin Pract 2005;9: 130-7.

[20] Poulin MJ, Cortese L, Williams R, Wine N, Mclntyre RS. Atypical antipsychotics in psychiatry practice: practical implications for clinical monitoring. Can J Psychiatry 2005;50:555-62.

[21] Cohn TA, Sernyak MJ. Metabolic monitoring for patients treated with antipsychotic medications. Can J Psychiatry 2006;51:492-501.

[22] Lean ME, Pajonk FG. Patients on atypical antipsychotic drugs: another high-risk group for type 2 diabetes. Diabetes Care $2003 ; 26: 1597-605$

[23] Scheen AJ, De Hert M. Diabète sucré iatrogène : l'exemple des antipsychotiques atypiques. Rev Med Liège 2005;60:455-60.

[24] Kohen D. Diabetes mellitus and schizophrenia: historical perspective. Br J Psychiatry 2004;184(Suppl 47):S64-6.

[25] De Hert M, Van Winkel R, Van Eyck D, Hanssens L, Wampers M, Scheen A, et al. Prevalence of the diabetes, metabolic syndrome and metabolic abnormalities in schizophrenia over the course of the illness: a cross-sectional study. Clin Pract Epidemiol Mental Health 2006;2:14 (27 June 2006).

[26] Regenold WT, Thapar RK, Marano C, Gavirnemi S, Kondapavuluru PV. Increased prevalence of type 2 diabetes mellitus among psychiatric inpatients with bipolar I affective and schizoaffective disorders independent of psychotropic drug use. J Affect Disord 2002;70:19-26.

[27] Van Winkel R, De Hert M, Van Eyck D, Hanssens L, Wampers M, Scheen A, et al. Prevalence of diabetes and the metabolic syndrome in a sample of patients with bipolar disorder. Bipolar Disord 2007 (in press).

[28] Hedenmalm K, Hagg S, Stahl M, Mortimer O, Spigset O. Glucose intolerance with atypical antipsychotics. Drug Saf 2002;25:1107-16.

[29] Melkersson K, Dahl M-L. Adverse metabolic effects associated with atypical antipsychotics. Literature review and clinical implications. Drugs 2004;64:701-23.

[30] Newcomer JW, Haupt DW. The metabolic effects of antipsychotic medications. Can J Psychiatry 2006;51:480-91.

[31] Koller EA, Cross JT, Doraiswamy PM, Malozowski SN. Pancreatitis associated with atypical antipsychotics: from the Food and Drug Administration's MedWatch surveillance system and published reports. Pharmacotherapy 2003;23:1123-30.

[32] Koller E, Schneider B, Bennett K, Dubitsky G. Clozapine-associated diabetes. Am J Med 2001;111:716-23.

[33] Koller EA, Doraiswamy PM. Olanzapine-associated diabetes mellitus. Pharmacotherapy 2002;22:841-52.

[34] Koller EA, Cross JT, Doraiswamy PM, Schneider BS. Risperidone-associated diabetes mellitus: a pharmacovigilance study. Pharmacotherapy 2003;23:735-44.

[35] Koller EA, Weber J, Doraiswamy PM, Schneider BS. A survey of reports of quetiapine-associated hyperglycemia and diabetes mellitus. J Clin Psychiatry 2004;65:857-63.

[36] Sernyak MJ, Leslie DL, Alarcon RD, Losonczy MF, Rosenheck R. Association of diabetes mellitus with use of atypical neuroleptics in the treatment of schizophrenia. Am J Psychiatry 2002;159:561-6.

[37] Haddad PM. Antipsychotics and diabetes: review of non-prospective data. Br J Psychiatry Suppl 2004;47:S80-6.

[38] Koro CE, Fedder DO, L'Italien GJ, Weiss S, Magder LS, Kreyenbuhl J, et al. An assessment of independent effect of olanzapine and risperidone on risk of diabetes among patients with schizophrenia: population based nested case-control study. BMJ 2002;325:243-5.

[39] Kornegay CJ, Vasilakis-Scaramozza C, Jick H. Incident diabetes associated with antipsychotic use in the United Kingdom general practice research database. J Clin Psychiatry 2002;63:758-62.

[40] Gianfrancesco F, White R, Wang RH, Nasrallah HA. Antipsychotic-induced type 2 diabetes: evidence from a large health plan database. J Clin Psychopharmacol 2003;23:328-35.

[41] Buse JB, Cavazzoni P, Hornbuckle K, Hutchins D, Breier A, Jovanovic L. A retrospective cohort study of diabetes mellitus and antipsychotic treatment in the United States. J Clin Epidemiol 2003;56:164-70.

[42] Lieberman JA, Phillips M, Gu H, Stroup S, Zhang P, Kong L, et al. Atypical and conventional antipsychotic drugs in treatment-naive first-episode schizophrenia: a 52-week randomized trial of clozapine vs. chlorpromazine. Neuropsychopharmacol 2003;28:995-1003.

[43] Holt RIG, Peveler RC. Antipsychotic drugs and diabetes: an application of the Austin Bradford Hill criteria. Diabetologia 2006;49:1467-73.

[44] Lieberman JA, Stroup TS, McEvoy JP, et al., For the Clinical Antipsychotic Trials of Intervention Effectiveness (CATIE) Investigators. Effectiveness of antipsychotic drugs in patients with chronic schizophrenia. N Engl J Med 2006;353:1209-23.

[45] Scheen AJ, De Hert MA, Hanssens L, Wampers M, van Winkel R, Van Eyck D, et al. (Abstract) Anomalies de la tolérance au glucose chez les patients schizophrènes traités par antipsychotiques de seconde génération : étude comparative prospective de trois mois. Diabetes Metab 2007;68(Suppl 1):1S129.

[46] De Hert M, Hanssens L, Van Winkel R, Wampers M, Van Eyck D, Scheen A, et al. Reversibility of antipsychotic treatment-related diabetes in patients with schizophrenia. A case series of switching to aripiprazole. Diabetes Care 2006;29:2329-30.

[47] Ader M, Kim SP, Catalano KJ, Ionut V, Hucking K, Richey JM, et al. Metabolic dysregulation with atypical antipsychotics occurs in the absence of underlying disease: a placebo-controlled study of olanzapine and risperidone in dogs. Diabetes 2005;54:862-71. 
Published in: Diabetes \& Metabolism (2007), vol. 33, iss. 3, pp. 169-75.

Status: Postprint (Author's version)

[48] Johnson DE, Yamazaki H, Ward KM, Schmidt AW, Lebel WS, Treadway JL, et al. Inhibitory effects of antipsychotics on carbacholenhanced insulin secretion from perifused rat islets. Role of muscarinic antagonism in antipsychotic-induced diabetes and hyperglycemia. Diabetes 2005;54: 1552-8.

[49] Gough S, Pelever R. Diabetes and its prevention: pragmatic solutions for people with schizophrenia. Br J Psychiatr 2004;184:S106-11.

[50] De Hert M, van Eyck D, De Nayer A. Metabolic abnormalities associated with second generation antipsychotics: fact or fiction? Development of guidelines for screening and monitoring. Int Clin Psychopharmacol 2006;21(Suppl 2):S11-5. 